\title{
A PROBLEMÁTICA DA RESPONSABILIDADE CIVIL DO PET SHOP, MÉDICO E CLÍNICA VETERINÁRIA PELOS DANOS CAUSADOS AOS ANIMAIS
}

\author{
Carlos Alexandre Moraes ${ }^{1}$ \\ Marta Beatriz Tanaka Ferdinand ${ }^{2}$
}

RESUMO: O presente artigo trata da problemática relacionada à responsabilidade civil do pet shop, médico e clínica veterinária pelos danos causados aos animais. Trata-se de uma relação de consumo, portanto, regida pelo Código de Defesa do Consumidor, contudo, mencionada legislação estabelece dois tipos de responsabilidade, a subjetiva e objetiva, dependendo do causador do dano. Por fim, serão apresentadas diversas decisões que adotaram ora a responsabilidade civil subjetiva, ora a responsabilidade civil objetiva.

PALAVRAS-CHAVE: Prestação de serviços; Animais; Civil; Danos; Indenização.

\section{THE PROBLEMATIC OF CIVIL RESPONSIBILITY OF PET SHOP, DOCTOR AND VETERINARY CLINICS FOR THE DAMAGE CAUSED TO ANIMALS}

ABSTRACT: The present article deals with the problems related to civil liability of the pet shop, medical and veterinary clinic for the damages caused to the animals. This is a consumer relationship, therefore, governed by the Consumer Protection Code, however, said legislation establishes two types of responsibility, subjective and objective, depending on the cause of the damage. Finally, a number of decisions will be presented, which have adopted either subjective liability or objective civil liability.

KEYWORDS: Provision of services; Animals; Civil; Damage; Indemnification.

\section{INTRODUÇÃO}

O tema "erro profissional e os animais" é de grande relevância, uma vez que a sociedade passou a ter mais informações a respeito de seus direitos, e as ações de indenizações contra os profissionais liberais (advogados, enfermeiros, farmacêuticos, fisioterapeutas, fonoaudiólogos, médicos, médicos veterinários, odontólogos, terapeutas ocupacionais e etc.) e prestadores de serviços tornaram-se fato comum.

Dessa forma, em razão da lacuna existente sobre o tema proposto, o presente estudo torna-se de extrema importância não apenas para os médicos veterinários, proprietários e funcionários das clínicas veterinárias e de pet shops, mas, também, para os acadêmicos do

\footnotetext{
${ }^{1}$ Docente do curso de graduação em Direito do UniCesumar. Mestre em Ciências Jurídicas pelo UniCesumar. Doutor em Ciências da Educação - UPAP. Doutorando em Função Social do Direito - FADISP.

2 Professora e Coordenadora do NPJ do UniCesumar. Mestra em Ciências Jurídicas pelo UniCesumar. Doutoranda em Função Social do Direito - FADISP.
} 
curso de medicina veterinária, uma vez que possibilita o conhecimento de informações importantes na área da responsabilidade civil aplicada aquela atividade profissional.

Para tanto, buscou-se fundamentação doutrinária e jurisprudencial, a fim de identificar a existência de normas a respeito do tema proposto. É clara a omissão do ordenamento jurídico quanto ao status jurídico dos animais, pois segundo o Código Civil brasileiro, são qualificados como coisas e pelo Código de Defesa do Consumidor são identificados como produto, não sendo titular de um tratamento adequado da forma que merecem.

Para reflexão: quando da prestação de serviços veterinários o animal deve ser tratado como qualquer "coisa" ou "produto"? Aquele merece tratamento jurídico diferenciado, por ser um ser vivo que tem sentimentos e é capaz de demonstra-los? Aquele que causar danos ao animal deve ser compelido a indenizar o dono do animal? Quem sofre os danos (material, moral e estético) o animal ou seu proprietário?

Esse trabalho tratará da problemática da responsabilidade civil dentro do âmbito da medicina veterinária (pet shop, clínica e médico veterinário), visto que no ordenamento jurídico brasileiro há previsão de duas formas de responsabilidade civil daqueles, uma responsabilidade civil subjetiva, fundamentada na culpa e uma segunda, a responsabilidade civil objetiva, que despreza a negligência, a imprudência e a imperícia, considerando apenas o risco da atividade desenvolvida pelo autor do dano.

Por fim, a pesquisa do tema justifica-se por ser relevante para a sociedade como para os profissionais da área da medicina veterinária e para sua realização foi utilizado o método teórico, no intuito de fundamentar as posições tomadas acerca do tema.

\section{DA RESPONSABILIDADE CIVIL}

\subsection{CONCEITO}

O termo responsabilidade civil significa a obrigação de reparar o dano causado à outra pessoa. A ideia de responsabilidade civil está fundamentada no princípio do neminem laedere (a ninguém se deve lesar). São vários os conceitos encontrados para a terminologia "responsabilidade civil", pode-se citar Miguel Maria de Serpa Lopes ensina que "responsabilidade significa a obrigação de reparar um prejuízo, seja por decorrer de uma culpa ou de uma outra circunstância legal que a justifique, como a culpa presumida, ou por uma circunstância meramente objetiva" (LOPES, 1961, p. 188-189).

Para Adauto de Almeida Tomaszewski imputar a responsabilidade a alguém, é considerar-lhe responsável por alguma coisa, fazendo-o responder pelas consequências de uma conduta contrária ao dever, sendo responsável aquele indivíduo que podia e devia ter agido de outro modo (TOMASZEWSKI, 2004, p. 245). Sendo assim, se o médico veterinário, no exercício de sua atividade profissional, causar dano, como, por exemplo, a morte do animal não humano de outrem terá que indenizá-lo, como já decidiu o Tribunal de Justiça do Ceará: 
CALAZAR. DEVOLUÇÃO DE UM DOS ANIMAIS. DEVOLUÇÃO DO VALOR PAGO. NÃO DEMONSTRAÇÃO. CONDENAÇÃO. DESPESAS COM TRATAMENTO. RESSARCIMENTO. MORTE DO SEGUNDO CANINO. DANO MORAL. CARACTERIZADO. CONDENAÇÃO MANTIDA. RECURSO CONHECIDO E PARCIALMENTE PROVIDO. 1. A ação foi interposta pelo comprador de dois animais da espécie canina que tiveram diagnosticada a incubação de doença incurável (calazar), tendo se devolvido a fêmea adulta, mas mantido o filhote por inconclusão quanto à contaminação, mas que depois feneceu pela mesma causa; 2. Sentença condenatória de reembolso do valor pago pela fêmea que foi devolvida ao canil ( $\mathrm{R}$ \$ 2.000,00), ressarcimento das despesas havidas com a manutenção do animal e dano moral decorrente da frustração do negócio, valor fixado em $\mathrm{R} \$ 1.000,00$ (mil reais); 3. Recurso de apelação impugnando: A) a condenação de reembolso da compra da cadela adulta, afirmando haver prova de tal procedimento anterior à propositura da ação e no ato de devolução do animal ao canil; b) a não obrigatoriedade do ressarcimento médico-veterinário, e; c) o dano moral arbitrado, sua ocorrência e valoração; 4. A apelação limita a amplitude do efeito devolutivo ao Tribunal, não havendo discussão quanto à responsabilidade ou a obrigação de indenizar; 5 . O promovido não logrou êxito na constituição de prova hábil a demonstrar o fato extintivo do direito autoral referente à devolução do dinheiro dado pela compra da fêmea adulta que foi devolvida ao canil, sendo seu o ônus probandi; 6 . A testemunha ouvida em juízo não confirma o pagamento e os extratos de saque de valores de terceiro não condizem e não foram confirmados em juízo, sendo infrutífera a indução probatória; 7. O ressarcimento das despesas médico-veterinárias deve refletir apenas aquilo que foi dispendido no tratamento da doença, não se podendo debitar ao vendedor as despesas relativas à manutenção do animal, como alimentação, banhos e tosas, que não se relacionam com o alegado vício oculto (calazar); 8. O dano moral se mostra cabível, sendo presenciado por testemunha o sofrimento familiar pela morte dos cães, animais de estimação, denotandose o apego e laço afetivo; 9. Quantum indenizatório fixado dentro da normalidade, não se considerando aviltante ou demasiado, cumprindo sua função reparadora, preventiva e didática, dentro da razoabilidade e tendo em conta os valores envolvidos. 10. Recurso de apelação conhecido e parcialmente provido, apenas para excluir da condenação as despesas não relacionadas ao tratamento médico-veterinário da doença apresentada (calazar). (TJCE; APL 0044795-03.2013.8.06.0064; Primeira Câmara Cível; Rel. Des. Paulo Francisco Banhos Ponte; DJCE 12/06/2015; Pág. 6)

Nesse caso, o médico-veterinário foi condenado a devolver os valores recebidos de $\mathrm{R} \$$ 2.000,00 (dois mil reais), e mais $\mathrm{R} \$ 1.000,00$ (hum mil reais) a título de danos morais, devido à frustação do negócio.

\section{ORIGENS DA RESPONSABILIDADE CIVIL}

No entender de Flávio Tartuce "A responsabilidade civil surge em face do descumprimento obrigacional, pela desobediência de uma regra estabelecida em um contrato, 
ou por deixar determinada pessoa de observar um preceito normativo que regula a vida" (TARTUCE, 2016, p. 310). No primeiro caso, o descumprimento das cláusulas contratuais, no caso de um pet shop, deixar de realizar o que foi pactuado na prestação de serviço; e, na segunda situação, faz referência que ninguém deve causar danos à outra pessoa.

Conta à história, que as sociedades primitivas já conheciam as normas de condutas, e quem as violasse era punido, inclusive com a morte, como ocorria, por exemplo, com o arquiteto que construísse uma casa e esta viesse a desabar ocasionando a morte de alguém, conforme o art. 229 do Código de Hamurabi.

Nessa época, vigorava a vingança coletiva e, posteriormente, a privada, ou seja, o mal pelo mal. A responsabilidade civil evoluiu, passou pela vingança coletiva até chegar ao direito contemporâneo, senão a justiça pelo Estado, em que cabe ao Poder Estatal punir os transgressores das normas.

O Código de Hamurabi pode ser considerado o primeiro código escrito a mencionar a responsabilidade civil do profissional liberal, uma vez que já regulava a atividade profissional do médico e do arquiteto.

Dessa forma, pode-se concluir que a responsabilidade civil foi gerada junto com a sociedade, pois, em todos os momentos da história, é possível encontrar normas que estabelecem que o causador do dano seja responsável pelo prejuízo causado a outrem.

\title{
4. OS ELEMENTOS DA RESPONSABILIDADE CIVIL
}

A doutrina é majoritária no sentido de que não existe responsabilidade civil sem a produção de um dano. Por exemplo, o médico veterinário que realiza tratamento incorreto, como no caso abaixo:

\begin{abstract}
APELAÇÃO. INDENIZAÇÃO POR DANOS MATERIAIS E MORAIS. PRESTAÇÃO DE SERVIÇOS. MÉDICO VETERINÁRIO. ERRO MÉDICO. CERATOCONJUNTIVITE SECA. RELAÇÃO DE CONSUMO. RESPONSABILIDADE CIVIL SUBJETIVA. ART. $14, \S 4^{\circ}$, DO CDC. Inversão do ônus da prova (CDC, art. $\left.6^{\circ}, \mathrm{III}\right)$. Hipossuficiência técnica do consumidor. Ausência de provas da regularidade do serviço prestado pela ré. Dever de indenizar reconhecido. DANO MATERIAL. Ressarcimento devido mediante a apresentação de recibos de compra dos medicamentos utilizados para suprir a produção de lágrimas do animal. DANO MORAL NÃO CONFIGURADO. Ausência de constrangimento ou dissabor superior ao usual. SUCUMBÊNCIA RECÍPROCA. Recurso provido em parte. (TJSP; APL 0220031-39.2009.8.26.0100; Ac. 7802724; São Paulo; Vigésima Nona Câmara de Direito Privado; Rel. Des. Hamid Bdine; Julg. 27/08/2014; DJESP 03/09/2014)
\end{abstract}

No caso supramencionado, o médico veterinário foi condenado a pagar uma indenização em razão dos danos materiais pelo erro na prestação de serviço ao animal em razão da ceratoconjutivite seca.

Para que o profissional liberal (médico veterinário), seja responsável por uma indenização, é necessário à produção de um prejuízo, já que, conforme julgamento do 
Tribunal de Justiça de São Paulo, a falta de um dano não gera o dever de indenização "Somente danos diretos e efetivos, por efeito imediato do ato culposo, encontram no Código Civil suporte de ressarcimento. Se dano não houver, falta matéria para a indenização. Incerto e eventual é o dano quando resultaria de hipotético agravamento da lesão" (TJSP - 1. C. AP. - Rel. Octávio Stucchi - j. 20.08.1995 - RT 612/44).

Contudo, o dano não é o único elemento necessário para que ocorra o dever de indenizar. No conceito de responsabilidade civil facilmente são identificados 04 (quatro) elementos: a) ação; b) culpa; c) nexo de causalidade; e o d) dano. Existindo esses requisitos em um determinado caso, surge para a vítima o direito de buscar uma reparação pelos danos sofridos. No caso da prestação de serviços do pet shop, do médico e da clínica veterinária a "vítima" é o animal, pois é este que sofre os danos, como, por exemplo, a morte em razão do serviço prestado ou a amputação da orelha, entretanto, o direito, estabelece que o lesado é o proprietário do animal. Dessa forma, fundamentou o Tribunal de Justiça de Minas Gerais:

RESPONSABILIDADE CIVIL. Erro médico-veterinário Alegação da demandante de diagnóstico equivocado e de realização de cirurgia desnecessária. Sentença que reconheceu a responsabilidade civil dos requeridos, ante a falta de comprovação de que os tratamentos a que a cadela pertencente à autora foi submetida antes da correta identificação de sua moléstia eram necessários. Insurgência da requerente restrita à abrangência dos danos materiais, e ao indeferimento do pedido de indenização por danos morais. Prejuízos de ordem patrimonial devem abrangem todos os gastos desnecessários efetuados para o tratamento da cachorra. Inexistência, porém, de dano moral indenizável. Aborrecimento causado à demandante não caracteriza sofrimento intenso passível de reparação Recurso parcialmente provido. (TJSP; APL 4001037-50.2013.8.26.0224; Ac. 7519665; Guarulhos; Sexta Câmara de Direito Privado; Rel. Des. Francisco Loureiro; Julg. 28/04/2014; DJESP 15/05/2014).

Adverte Flávio Tartuce que “[...] que a conduta humana pode ser causada por uma ação (conduta positiva) ou omissão (conduta negativa) voluntária ou por negligência, imprudência ou imperícia, modelos jurídicos que caracterizam o dolo e a culpa, respectivamente (TARTUCE, 2016, p. 361).” Sendo assim, a conduta humana é elemento essencial para caracterização da responsabilidade civil.

A conduta é realizada por uma ação positiva (ação) ou negativa (omissão) que sem essas é impossível dar origem a um dano. O comportamento pode ser consectário da prática de atos ilícitos e lícitos.

Dessa forma, o pet shop, o médico e a clínica veterinária podem ser responsáveis por danos que um animal sofrer tanto pela ação, quanto pela omissão daqueles, assim "Quem, por omissão voluntária, causa prejuízo a outrem, fica obrigado a reparar o dano" (TJPR - 3. C. - AP. rel. Said Zantune - j. 18.09.79 - RT 549/203) (destacou-se). Explica Sergio Cavalieri Filho (CAVALIERI FILHO, 2008, p. 24) a diferença entre a conduta positiva (ação) e a negativa (omissão):

A ação é a forma mais comum de exterioração da conduta, porque, fora do domínio contratual, as pessoas estão obrigadas a abster-se da prática de atos que possam lesar o seu semelhante, de sorte que a violação desse dever geral de abstenção se obtém através de um fazer. Consiste, pois, a ação em um movimento corpóreo comissivo, um comportamento positivo, como a destruição de uma coisa alheia, a morte ou lesão corporal causada em 
alguém, e assim por diante. Já, a omissão, forma menos comum de comportamento, caracteriza-se pela inatividade, abstenção de alguma conduta devida. Vieira dizia, com absoluta propriedade, que omissão é aquilo que se faz não fazendo.

Por exemplo, responde pelos danos causados por ação, a clínica que não acerta o valor da consulta antes da prestação de serviços e que permite que a consulta seja realizada por pessoas que não esteja habilitada (estagiário) para realizar serviço de atendimento:

\section{JUIZADO ESPECIAL CÍVEL. CONSUMIDOR. SERVIÇOS VETERINÁRIOS. PRELIMINAR DE NULIDADE DA CITAÇÃO. REJEITADA. VEROSSIMILHANÇA DAS ALEGAÇÕES DOS AUTORES. FALHA NA PRESTAÇÃO DO SERVIÇO. RESTITUIÇÃO DO VALOR PAGO. DANO MORAL CONFIGURADO. QUANTUM RAZOÁVEL E PROPORCIONAL. RECURSOS CONHECIDOS E NÃO PROVIDOS. 1. Preliminarmente,} insta salientar que não há que se falar em nulidade de citação do segundo requerido e ora recorrente, posto que o comparecimento espontâneo do réu à audiência convalida o ato citatório, nos termos do artigo $18, \S 3^{\circ}$ da Lei $n^{\circ}$ 9.099/95. Preliminar rejeitada. 2. Mérito. Há verossimilhança nas alegações da parte recorrida, na medida em que os recorrentes não se desincumbiram do seu ônus de provar que efetivamente cobraram o preço, no início do atendimento ao cão, da quantia de $\mathrm{R} \$ 140,00$ e não $\mathrm{R} \$ 50,00$ como alegado pelos recorridos, que se sentiram por essa razão ludibriados. 3. Com efeito, na ata de audiência acostada à fl. 21, verifica-se que os recorrentes afirmam existir câmeras de segurança no estabelecimento. Todavia, não trouxeram aos autos as respectivas filmagens. Aplicação do princípio da distribuição dinâmica do ônus da prova, nos termos do art. 373, § $1^{\circ}$, do CPC/2015. 4. Os recorrentes se contradizem quando afirmam que o senhor Bruno Souto de Oliveira é veterinário da clínica, quando em verdade, o rapaz é estagiário. Houve falha na prestação do serviço. A falha do serviço ocorreu, tanto em razão da ausência de acerto prévio do preço da consulta, quanto pela realização da consulta veterinária por profissional ainda não habilitado (estagiário). 5. Conquanto as filmagens trazidas aos autos à fl. 27 demonstrem que o primeiro recorrido estava bastante nervoso, o conjunto probatório revela que ambos os consumidores foram indevidamente impedidos de deixar a clínica, configurando-se nesse ponto, o dano moral, posto que os fatos extrapolaram o simples descontentamento cotidiano, afetando mesmo a honra subjetiva dos autores pelo cerceamento da sua liberdade, 6. Quanto ao valor arbitrado pelo Juízo de origem a título de danos morais ( $\mathrm{R} \$ 3.000,00)$, este deve ser mantido, tendo em vista que se encontra dentro dos padrões da razoabilidade e proporcionalidade. Referido valor foi fixado em consideração à extensão do dano e à capacidade das partes, além de manter o condão de inibição da prática ilícita por parte da ré (punitive damage), pela conduta ora reportada (cerceamento de liberdade e falha na prestação de informação clara e objetiva). Anoto ainda que o valor fixado não é apto a gerar o enriquecimento ilícito do recorrido, nem o empobrecimento da empresa recorrente. 7. Recurso CONHECIDO e NÃO PROVIDO. Sentença mantida pelos seus próprios fundamentos. Custas e honorários pelos recorrentes vencidos, estes últimos fixados em $10 \%$ (dez por cento) do valor da condenação, consoante art. 55 da Lei $n^{\circ}$ 9.099/95. Súmula de julgamento que servirá de acórdão, na forma do artigo 46 da Lei 
no 9.099/95. (TJDF; ACJ 2015.04.1.006806-8; Ac. 983.123; Segunda Turma Recursal dos Juizados Especiais; Rel. Des. João Fischer; Julg. 23/11/2016; DJDFTE 29/11/2016)

O segundo elemento da responsabilidade civil é a culpa. A respeito da culpa, Flávio Tartuce ensina que "a culpa pode ser conceituada como sendo o desrespeito a um dever preexistente, não havendo propriamente uma intenção de violar o dever jurídico, que acaba sendo violado por outro tipo de conduta" (TARTUCE, 2016, p. 364). O agente causador do dano, no caso de culpa, não precisa ter a intenção de causar o dano, esse pode ser causado pelo descuido. A culpa é uma conduta que provem de negligência, imprudência ou até imperícia, sem propósito de lesar, mas da qual resulta um dano.

RECURSO INOMINADO. REPARAÇÃO POR DANOS MATERIAIS E MORAIS. ANIMAL DE ESTIMAÇÃO. ÓBITO APÓS A REALIZAÇÃO DE CIRURGIA DE CASTRAÇÃO. LABRADORA DE CINCO ANOS. CIRURGIA REALIZADA EM LOCAL INADEQUADO. RESPONSABILIDADE DA VETERINÁRIA EVIDENCIADA. DANOS MORAIS CONFIGURADOS. QUANTUM INDENIZATÓRIO ARBITRADO EM R\$ 7.000,00 QUE VAI MANTIDO, ANTE AS PECULIARIDADES DO CASO EM APREÇO. 1. Não há necessidade de conversão do feito para a justiça comum, ante a impossibilidade de realização de perícia técnica, em face do lapso temporal transcorrido entre a morte do animal e o presente momento. 2. Ainda que não fosse o problema do lapso temporal, a perícia técnica se mostra desnecessária, pois incontroverso que o animal de estimação da autora veio a óbito em consequência da cirurgia de castração realizada pela requerida. 3. Além de não existir qualquer indício de negligência dos donos no pós-operatório, a veterinária sequer comprovou que prestou os esclarecimentos necessários acerca dos cuidados que deveriam ministrar ao cão nos primeiros dias após a cirurgia, situação que por si só já afastaria eventual responsabilidade dos autores, uma vez que o dever de informação incumbia à requerida. 4. $\underline{\mathrm{A}}$ culpa da veterinária, a sua negligência, imprudência e imperícia podem ser constatadas pelo fato de ter realizado um procedimento cirúrgico no estabelecimento comercial registrado como consultório veterinário, PET shop e comércio de artigos de animais (fls. 37 e 55), o que é proibido pelo Conselho Federal de Medicina. De acordo com a resolução no 1015/12 (fls. 46/54), somente os estabelecimentos registrados como clínicas veterinárias é que tem condições e autorização para a realização de procedimentos cirúrgicos, hipótese na qual a ré não se enquadra. 5. Ainda, a teor das mensagens trocadas às fls. 56 entre a autora e a ré, verifica-se claramente que a requerida assumiu a responsabilidade ao negociar uma indenização à autora pelo fato ocorrido. 6. É inegável a dor e o sofrimento de uma família ao perder seu animal de estimação de cinco anos de idade, de modo que os danos morais foram corretamente arbitrados. 7. Apesar de não haver pedido expresso de redução do quantum de $\mathrm{R} \$ 7.000,00$ nas razões recursais, não seria o caso de redução, pois restou evidenciado que a requerida contrariou as disposições do conselho federal de medicina veterinária, situação grave que deve ser considerada no valor arbitrado a título de danos morais. Sentença mantida. Recurso improvido. (TJRS; RecCv 002099349.2015.8.21.9000; Uruguaiana; Quarta Turma Recursal Cível; Rel ${ }^{a}$ Des $^{a}$ Glaucia Dipp Dreher; Julg. 28/08/2015; DJERS 01/09/2015) 
No presente caso supramencionado, ficou comprovada a existência da culpa da médica veterinária, uma vez que o animal faleceu em razão da prestação de serviços da médica, dessa forma, ficou caracterizada além do dano material, aquela foi condenada a indenizar em $\mathrm{R} \$$ 7.000,00 (sete mil reais) a título de dano moral pela morte do animal.

Se não for verificada há culpa (negligência, imprudência ou imperícia), não há que se falar em responsabilidade civil ou indenização, dessa forma, vem decidindo os tribunais brasileiros nos casos envolvendo a prestação de serviço de pet shop:

DIREITO CIVIL. RESPONSABILDADE CIVIL. PET SHOP. CULPA NÃO DEMONSTRADA. CONTRATO DE PRESTAÇÃO DE SERVIÇOS VETERINÁRIOS. 1 - Na forma do art. 46 da Lei ${ }^{\circ}$ 9.099/1995, a ementa serve de acórdão. Recurso próprio, regular e tempestivo. 2 Responsabilidade civil. Relação de Causalidade. Não resta demonstrada a causalidade entre o fato do serviço e o evento morte do animal de estimação, de modo que não se estabelece o liame de responsabilidade pretendido pelo autor. O vídeo (ID 858150) e os laudos apresentados (ID 858123 e 858171) não demonstram a relação de causalidade entre o serviço prestado e a morte do animal, pelo contrário, corroboram que houve pronto atendimento ao animal, não demonstrando, portanto, o defeito no serviço prestado pela ré. 3 - Dano moral. Responsabilidade civil. $\underline{\mathrm{O} \text { reconhecimento da }}$ responsabilidade civil por danos morais pressupõe a prática de ilícito ou fato objetivo causador de dano. Sem demonstração de ilegalidade não se acolhe pedido de indenização por danos morais (art. 186 do Código Civil). Sentença que se confirma pelos seus próprios fundamentos. 4 - Recurso conhecido e não provido. Custas e honorários, fixados em $\mathrm{R} \$ 800,00$, pelo recorrente vencido. 05. (TJDF; RInom 0707750-36.2016.8.07.0016; Primeira Turma Recursal dos Juizados Especiais; Rel. Juiz Aiston Henrique de Sousa; Julg. 12/12/2016; DJDFTE 16/12/2016; Pág. 532)

O terceiro elemento da responsabilidade civil é o nexo de causal ou nexo de causalidade, Flávio Tartuce é preciso na medida em que pontifica que "o nexo de causalidade ou nexo causal constitui o elemento imaterial ou virtual da responsabilidade civil, constituindo a relação de causa e efeito entre a conduta culposa ou o risco criado e o dano suportado por alguém" (TARTUCE, 2016, p. 374).

O nexo causal é o elo entre a ação e o dano. A clínica veterinária, o médico veterinário e o pet shop só vão ser condenados a indenizar um cliente, se ficar comprovado que entre a prestação de serviço daqueles e o dano sofrido pelo animal, tenha alguma relação, para essa relação é dada o nome de nexo causal ou nexo de causalidade:

RESPONDABILIDADE CIVIL. AUSENTE COMPLEXIDADE. COMPETÊNCIA DOS JUIZADOS ESPECIAIS CÍVEIS. PRESTAÇÃO DE SERVIÇO MÉDICO-VETERINÁRIO EM PET SHOP. CASTRAÇÃO DE ANIMAL. AUSÊNCIA DE AUTORIZAÇÃO PELO CONSELHO REGIONAL DE MEDICINA VETERINÁRIA. A complexidade do feito não se verifica considerando o farto material probatório produzido, o que demonstra a prescindibilidade de exame técnico, até mesmo a impossibilidade desse diante do ato cirúrgico posterior. A requerida realizou ato cirúrgico, castração de animal, em seu estabelecimento, sem autorização do conselho regional de medicina veterinária. E, considerando o material probatório, laudos dos profissionais que atenderam o animal, apontando irregularidades na castração realizada, resta suficiente comprovado o dano e 
o nexo causal, impondo-se o ressarcimento do prejuízo sofrido. Dano moral mantido em seu aspecto punitivo-pedagógico, estando a indenização compensatória mensurada, $\mathrm{R} \$ 1.500,00$, adequada à extensão lesiva da conduta. Sentença confirmada por seus próprios fundamentos, nos termos do artigo 46 da Lei dos juizados especiais cíveis. Recurso desprovido. (TJRS; RecCv 33867-37.2013.8.21.9000; Porto Alegre; Terceira Turma Recursal Cível; Rel. Des. Pedro Luiz Pozza; Julg. 12/12/2013; DJERS 17/12/2013)

Para que ocorra a obrigação de indenizar, é de suma importância que se prove a relação de causalidade, como no caso acima, onde ficou comprovado por laudos médicos que constataram irregularidades na castração realizada, demonstrando o nexo de causalidade entre a cirurgia de castração e o dano sofrido, dessa forma, a condenação, no valor de R $\$ 1.500,00$ (hum mil e quinhentos reais), pelos danos morais causados.

Convém salientar, como esclareceu Cristiane Gouveia de Barros o nexo de causalidade trata-se da "[...] conduta do agente causador do dano com culpa ou sem culpa - risco e o evento danoso, sem o comportamento do agente causador do dano ou o risco não se verificaria o evento danoso, é uma relação lógico-jurídica da causa e efeito, denominada de relação de causalidade (BARROS, 2002. p. 101)".

Por fim, o último elemento da responsabilidade civil é o dano, ou seja, é o prejuízo causado no patrimônio de alguém. O patrimônio pode ser de origem material ou moral.

Conforme os ensinamentos de Flávio Tartuce "em regra, não há responsabilidade civil sem dano [...] (TARTUCE, 2016, p. 392)." Só se pode falar em responsabilidade civil, se produzir um dano a indenizar, pois a sua função é a reposição decorrente da diminuição do patrimônio de alguém, "a jurisprudência é pacífica no entendimento de que não se pode falar em indenização quando o autor não comprova a existência do dano" (RT 568/167).

Flávio Tartuce acentua que "os danos patrimoniais ou materiais constituem prejuízos, perdas que atingem o patrimônio corpóreo de uma pessoa natural, pessoa jurídica ou ente despersonalizado" (TARTUCE, 2016, p. 395). Os danos patrimoniais são divididos em danos emergentes que se caracterizam pela diminuição do patrimônio do lesado e nos lucros cessantes, os valores que o lesado deixou de ganhar em razão da prestação de serviços do pet shop, do médico ou da clínica veterinária.

$\mathrm{Na}$ decisão abaixo o pet shop foi condenado por dano patrimonial e dano moral, em relação a morte do animal:

MORTE DE ANIMAL ENCAMINHADO À PET SHOP. Nexo de causalidade demonstrado. Ônus da prova que era da ré quando à causa mortis do animal, eis que foi quem o encaminhou à clínica veterinária onde veio a óbito. Hipótese em que era ônus da empresa requerida, buscando excluir o nexo de causalidade, comprovar que a morte não se deu em virtude de sua conduta. Consumidora que provou ter entregue o animal em condições de saúde à requerida para procedimento simples de banho e secagem. Sentença de improcedência reformada. Reconhecimento do direito à indenização por dano material e extra-patrimonial. Deram provimento ao recurso. (TJRS; RCív 71001711985; Ijuí; Primeira Turma Recursal Cível; Rel. Des. Heleno Tregnago Saraiva; Julg. 18/12/2008; DOERS 29/12/2008; Pág. 36)

Em um primeiro momento, a reparação do dano moral não era reconhecida pela doutrina e nem pela jurisprudência brasileira, período da negação ao dano extrapatrimonial, a argumentação era que não se repara a dor, todavia, desde meados dos anos de 1920, vozes se 
levantaram dentro do Supremo Tribunal Federal defendendo a possibilidade de reparação do dano moral, como Pedro Lessa e mais tarde Orozimbo Nonato. Pelo menos desde o ano de 1944 a doutrina também vem colaborando na defesa da indenização dos danos morais ${ }^{3}$.

A possibilidade da reparação do dano moral no Brasil foi positivada com a promulgação da Constituição Federal de 1988, tratam de uma lesão aos direitos da personalidade, esses por suas próprias razões não pode ser mensurado financeiramente, muito menos ser reparados, contudo, o intuito é compensar os danos causados pela violação do princípio da dignidade humana ou dos direitos da personalidade, que foram agredidos pela conduta de outra pessoa.

No mesmo sentido, para Maria Helena Diniz o dano moral "[...] vem a ser a lesão de interesses não patrimoniais de pessoa física ou jurídica, provocada pelo fato lesivo" (DINIZ, 2011, p. 106). Participa do mesmo juízo, Wilson Melo da Silva, os danos morais são "[...] lesões sofridas pelo sujeito físico ou pessoa natural de direito em seu patrimônio ideal, entendendo-se por patrimônio ideal, em contraposição ao patrimônio material, o conjunto de tudo aquilo que não seja suscetível de valor econômico" (SILVA, 1969, p. 13). Os danos morais se apresentam também na angústia, causada por todo tipo de ofensa, inclusive apela morte do animal ou pelo desaparecimento:

APELAÇÃO CÍVEL. AÇÃO DE INDENIZAÇÃO POR DANOS
MATERIAIS E M MORAIS. RESPONSABILIDADE CIVIL.
CONSUMIDOR. PET SHOP. MORTE DE ANIMAL DE ESTIMAÇÃO
APÓS PROCEDIMENTO DE BANHO E TOSA. SUPERLOTAÇÃO DE
ANIMAIS. LONGA ESPERA EM GAIOLA SEM MONITORAMENTO.
FALHA NA PRESTAÇÃO DE SERVIÇOS. DANO MORAL IN RE IPSA.
Os PET shops e clínicas veterinárias, na qualidade de prestadores de
serviços, respondem independentemente de culpa pelo serviço prestado de
forma defeituosa ao consumidor, nos termos do art. 14 do CDC.
Comprovado que o PET permaneceu na gaiola por aproximadamente 07
horas à espera do procedimento de banho e tosa, sem qualquer
monitoramento, há evidente violação ao dever de guarda, zelo e proteção,
inerentes à própria atividade da ré. Danos morais. Quantum minorado.
Adstrição aos princípios da razoabilidade e proporcionalidade, atentando
para a capacidade econômica das partes. A indenização deve ser fixada
considerando-se os elementos da lide, como os transtornos gerados, a
qualidade das pessoas em litígio e a capacidade econômica dos envolvidos,
atendendo aos objetivos da reparação civil, quais sejam, a compensação do
dano, a punição ao ofensor e a desmotivação social da conduta lesiva, sem
que gere um enriquecimento sem causa à vítima. Quantum indenizatório
minorado. Honorários advocatícios mantidos. Devem ser mantidos os
honorários fixados em percentual sobre o benefício econômico auferido com
a causa, atendendo aos requisitos do art. 20 , § $3^{\circ}$, do CPC, e levando em
consideração as diretrizes contidas nas alíneas "a", "b" e "c" do mesmo
dispositivo legal. Honorários advocatícios contratuais. Condenação ao

\footnotetext{
${ }^{3}$ BRASIL, Ávio. O dano moral no direito brasileiro. Rio de Janeiro: Livraria Jacinto Editora, 1944, p. 27. "acreditamos, assim, que, no dia em que se normatizarem, também, os planos do ressarcimento dos danos morais, aplicando, às várias hipóteses, fórmulas especiais determinadas por circunstâncias também especiais, atingiremos um ideal jurídico há muito almejado, derribandas que ficam as teorias presumistas dos que, como Gabba, acharam impossível descobrir um processo de medir o grau da sensação sofrida. Deste modo, chegaremos a acreditar, igualmente, que tal aplicação, como ordem jurídica, ou seja pelo avanço que rompe conceitos, ou seja pelos rumos novos e definitivos, do Direito, nesse sentido chegamos a acreditar que isso marcará, então, feito semelhante aos dos grandes instantes sociais."
} 
ressarcimento de $30 \%$ que corresponde ao valor contratado entre a autora e seu advogado a título de dano material. Inadmissibilidade. Recurso de apelação parcialmente provido. Não é cabível o pagamento de honorários advocatícios contratuais a título de perdas e danos, razão pela qual não deve ser essa verba incluída na condenação. Recurso conhecido e parcialmente provido. (TJMS; APL 0828960-66.2013.8.12.0001; Campo Grande; Quarta Câmara Cível; Rel. Des. Dorival Renato Pavan; DJMS 18/06/2015; Pág. 18)

DIREITO PRIVADO. APELAÇÃO DA AUTORA E RECURSO ADESIVO DO CORRÉU. PRESTAÇÃO DE SERVIÇO. "PET SHOP". ANIMAIS DE ESTIMAÇÃO DEIXADOS PARA BANHO E TOSA. CACHORROS QUE FORAM DEIXADOS NO QUINTAL DA PROPRIETÁRIA, SEM QUALQUER AVISO AOS MORADORES. DESAPARECIMENTO DOS ANIMAIS. DANO MORAL DEVIDO. PROCEDÊNCIA PARCIAL - QUANTUM INDENIZATÓRIO. MAJORAÇÃO. ADMISSIBILIDADE. Valor fixado em primeiro grau (R\$ $5.000,00)$ insuficiente para atender a dupla finalidade da indenização, comportando, pois, majoração ( $\mathrm{R} \$ 10.000,00)$, porém, afastando-se o valor pretendido pela recorrente. DANO MATERIAL. NÃO OCORRÊNCIA. Apelo da autora parcialmente provido e desprovido o recurso adesivo do réu. (TJSP; APL 0000949-30.2015.8.26.0024; Ac. 10182943; Andradina; Trigésima Quarta Câmara de Direito Privado; Rel. Des. Antonio Tadeu Ottoni; Julg. 15/02/2017; DJESP 23/02/2017).

Nos danos materiais, a indenização busca repor os bens lesionados ao seu estado anterior ou possibilitar ao cliente a reposição de outro bem semelhante ao destruído. No dano moral, ocorre uma satisfação do lesado por meio de um pagamento em dinheiro, que possa amenizar a dor, mas jamais restabelecer ou substituir o bem lesionado.

\section{RESPONSABILIDADE CIVIL OBJETIVA E RESPONSABILIDADE CIVIL SUBJETIVA}

A responsabilidade civil surgiu fundada essencialmente na doutrina da culpa. Assim, para que a pessoa que sofreu um dano fosse indenizada, era necessário provar a culpa do agente causador.

A responsabilidade civil subjetiva encontra sua justificativa na ideia de culpa (negligência, imprudência, imperícia) por parte do causador do dano, quer por meio de ação ou omissão, causa prejuízo à terceiro.

Com o desenvolvimento da sociedade e o consequente aumento dos casos de danos, que ficaram sem a reparação, evidenciou-se que a responsabilidade subjetiva era inadequada. Desse modo, reconheceu o legislador à obrigação de ressarcir o dano ao lesado, independentemente deste ter sido cometido sem culpa, o que chamou a doutrina de responsabilidade objetiva.

Por sua vez, a responsabilidade civil objetiva (teoria do risco) é caracterizada pelo desprezo do elemento culpa, busca-se apenas um nexo de causalidade entre o dano e a conduta do causador do dano.

A responsabilidade objetiva se explica pelo fato do agente, por meio de sua atividade ou comportamento, oferecer riscos de causar um dano a alguém; assim, terá que suportar os prejuízos causados independente de culpa. Silvio Rodrigues assevera que: 
Na responsabilidade objetiva a atitude culposa ou dolosa do agente causador do dano é de menor relevância, pois, desde que exista relação de causalidade entre o dano experimentado pela vítima e o ato do agente, surge o dever de indenizar, quer tenha este último agido ou não culposamente (RODRIGUES, 2002, p. 11).

Para essa teoria, basta demonstrar que determinada conduta causou um dano, tendo respaldo explicito no parágrafo único, do artigo 927 do Código Civil, que determina:

Art. 927. [...].

Parágrafo único: Haverá obrigação de reparar o dano, independentemente de culpa, nos casos especificados em lei, ou quando atividade normalmente desenvolvida pelo autor do dano implicar, por sua natureza, risco para os direitos de outrem.

Pode-se concluir que na responsabilidade objetiva o dever de reparar nasce independentemente da necessidade de se demonstrar a culpa, por força do dispositivo legal expresso ou de risco da atividade. Sendo assim, se a clínica veterinária prestar um serviço e em razão o animal vai a óbito, gera para aquela o dever de indenizar os danos causados.

\section{RESPONSABILIDADE CIVIL NA CONSTITUIÇÃO FEDERAL DE 1988}

A responsabilidade civil é um dos temas mais importante no direito, tanto que recebeu tratamento diferenciado na Constituição Federal brasileira de 1988, que estabelece a possibilidade de indenização por lesão ao patrimônio (material ou moral) do paciente como uma das cláusulas pétreas (que não podem sofrer propostas para alteração) existentes naquela Constituição. Os incisos, V e X, do art. 5. ${ }^{\circ}$ da Constituição Federal estabelecem que:

Art. 5. $^{\circ}$ - Todos são iguais perante a lei, sem distinção de qualquer natureza, garantindo-se aos brasileiros e aos estrangeiros residentes no País a inviolabilidade do direito à vida, à liberdade, à igualdade, à segurança e à propriedade, nos seguintes termos:

$(\ldots)$

$\mathrm{V}$ - é assegurado o direito de resposta, proporcional ao agravo, além da indenização por dano material, moral ou à imagem;

$(\ldots)$

$\mathrm{X}$ - são invioláveis a intimidade, a vida privada, a honra e a imagem das pessoas, assegurado o direito à indenização pelo dano material ou moral decorrente de sua violação;

Esses dois incisos prescrevem o dever que o causador do dano tem que indenizar os prejuízos causados a outrem, seja por dano à vida, à integridade física, à saúde ou por dano material, moral, estético e à imagem do indivíduo.

\section{RESPONSABILIDADE CIVIL NO CÓDIGO CIVIL}

Em princípio, todas as pessoas são responsáveis pelos atos por ela praticados capazes de ensejar reflexos jurídicos; assim, é fundamento da responsabilidade civil que todo dano merece ser indenizado. 
A noção de responsabilidade civil no Código Civil brasileiro está elencado no artigo 186. No primeiro momento do texto legal, "aquele que, por ação ou omissão voluntária, negligência ou imprudência, violar direito ou causar dano a outrem, ainda que exclusivamente moral, comete um ato ilícito", estabelece a noção de culpa.

Tal menção foi inspirada no artigo 1.382 do Código Civil francês "todo e qualquer ato do homem que causa um dano a outros obriga aquele que o ocasionou a repará-lo", trata-se da responsabilidade subjetiva. Todavia, o parágrafo único do artigo 927, do mesmo Código, traz as regras de aplicabilidade da responsabilidade civil objetiva, que assim ensina:

Art. 927. [...]

Parágrafo único: Haverá obrigação de reparar o dano, independentemente de culpa, nos casos especificados em lei, ou quando atividade normalmente desenvolvida pelo autor do dano implicar, por sua natureza, risco para os direitos de outrem.

Aqui se encontra evidenciada a responsabilidade civil objetiva. Diferentemente do Código Civil de 1916, havia adotado a teoria subjetiva, o atual Códex inova, pois trata tanto da responsabilidade civil objetiva, quanto da subjetiva ${ }^{4}$.

Há de se destacar que a tendência, tanto da jurisprudência, quanto da doutrina, no direito pátrio, é que se indenizem os danos causados de forma objetiva, ou seja, independentemente da culpa do agente do dano, bastando o nexo de causalidade entre a conduta e o dano sofrido pela vítima.

O Código Civil estabeleceu, ainda, que o juiz deverá considerar o grau de culpa do médico veterinário, do pet shop ou da clínica veterinária, no caso de uma condenação por danos causados, se a culpa daqueles for considerada leve ou média, deve o juiz considerar o disposto nos artigos 944 e 945 do Código Civil.

Art. 944. A indenização se mede pela extensão do dano.

Parágrafo único - Se houver excessiva desproporção entre a gravidade da culpa e o dano, poderá o juiz reduzir, equitativamente, a indenização.

Art. 945. Se a vítima tiver concorrido culposamente para o evento danoso, a sua indenização será fixada tendo-se em conta a gravidade de sua culpa em confronto com a do autor do dano.

Deverá ser reduzido o valor da indenização se, por acaso, o paciente tiver colaborado para o resultado danoso. Em fase recursal os tribunais pátrios vêm diminuindo o valor da condenação por danos morais, quando fica evidenciado que o cliente contribuiu para a produção do dano, como, por exemplos, quando demora em procurar o socorro para seu animal não humano. Pode-se concluir que, na culpa concorrente, o pet shop, veterinário, a clínica e o cliente descumprem o dever de cuidado, e, por isso, acabam gerando o evento danoso.

\section{RESPONSABILIDADE CIVIL DO PET SHOP, DA CLÍNICA VETERINÁRIA E DO MÉDICO VETERINÁRIO}

Até o advento do Código de Defesa do Consumidor, a responsabilidade civil era fundamentada no elemento culpa. Dessa forma, não bastava demonstrar que o agente tinha

${ }^{4}$ Art. 186 do CC. "Aquele que, por omissão, por ação ou omissão voluntária, negligência ou imprudência, violar direito e causar dano a outrem, ainda que exclusivamente moral, comete ilícito." 
realizado um ato danoso, era necessário provar que o agente tinha agido com culpa (negligência, imprudência ou imperícia)

A Lei n. ${ }^{\circ} 8.078 / 90$ traz uma novidade para a legislação pátria, consistente na responsabilidade civil objetiva. Assim sendo, envolvendo relação de consumo, não é necessário o elemento culpa, para que exista o dever de indenizar um dano; basta o nexo de causalidade entre a ação realizada e o dano ocorrido, conforme a teoria do risco ${ }^{5}$. A clínica veterinária que responde independentemente de culpa, pois sua responsabilidade será apurada de forma objetiva.

RECURSO INOMINADO. RESPONSABILIDADE CIVIL. ANIMAL DE ESTIMAÇÃO. DESAPARECIMENTO/FUGA DE GATO DA CLÍNICA VETERINÁRIA. FALHA NA PRESTAÇÃO DOS SERVIÇOS EVIDENCIADA. DEVER DE GUARDA NÃO OBSERVADO. DANOS MORAIS CONFIGURADOS. QUANTUM INDENIZATÓRIO REDUZIDO. Depreende-se do conjunto probatório colacionado aos autos, que a parte autora encaminhou o seu gato para realizar tratamento de saúde no estabelecimento da ré. Ocorre que o animal de estimação desapareceu/fugiu, não sendo mais encontrado, o que conduz à hipótese de falha na prestação dos serviços, diante da ausência de zelo na guarda. De acordo com o artigo 14 do CDC, os prestadores de servicos respondem de forma objetiva pelos danos causados ao consumidor por defeitos relativos à prestação dos serviços. Configurado está o dever de indenizar. Contudo, impõe-se o provimento parcial do recurso, com a redução do quantum arbitrado na origem ( $\mathrm{R} \$ 14.430,00$ - Fl. 43) para $\mathrm{R} \$ 8.000,00$ (oito mil reais), a fim de atender aos postulados da proporcionalidade e da razoabilidade e, em especial, considerando a capacidade econômica da ré, haja vista tratar-se de uma microempresa (fls. 53-59). A gravidade da conduta ilícita, a intensidade e a duração das consequências, a condição econômica da ofensora de suportar a indenização e o dúplice caráter da medida (pedagógico, para evitar a reiteração da conduta inadequada; e compensatório, mas sem ocasionar enriquecimento indevido) devem ser sopesados na quantificação dos danos imateriais, o que, então, justifica a minoração da indenização. Sentença reformada em parte. Recurso parcialmente provido. (TJRS; RecCv 0035862-17.2015.8.21.9000; Porto Alegre; Terceira Turma Recursal Cível; Rel ${ }^{a}$ Des ${ }^{a}$ Lusmary Fátima Turelly da Silva; Julg. 22/10/2015; DJERS 28/10/2015).

A responsabilidade civil do profissional liberal, por exemplo, o médico veterinário, é apurada de forma diferente da clínica e do pet shop, aquele só vai ser condenado a indenizar seu cliente se ficar comprovado que o dano que causou foi proveniente de negligência,

\footnotetext{
${ }^{5}$ SILVA, Luiz Cláudio, Responsabilidade Civil. teoria e prática das ações. Rio de Janeiro: Forense, 1998. p. 53. "O fornecedor de bens e serviços assume, por força do Código de Defesa do Consumidor, os riscos decorrentes de sua atividade profissional ou econômica, a ele é aplicada a Teoria do Risco do Empreendimento, pois com base nessa teoria todo aquele que se propõe a desenvolver qualquer atividade no campo do fornecimento de bens e serviços conseqüentemente tem a obrigação de responder pelos fatos e vícios resultantes dessa atividade econômica, não se questionando aí se concorreu ou não com culpa no evento danoso. Como bem definiu o professor Sério Cavalieri Filho, em sua doutrina de Responsabilidade Civil, p. 318: "Este dever é eminente ao dever de obediência às normas técnicas e de segurança, bem como aos critérios de lealdade, quer perante os bens e serviços ofertados, quer perante os destinatários dessas ofertas. A responsabilidade decorre do simples fato de dispor-se alguém a realizar atividade de produzir, estocar, distribuir e comercializar produtos ou executar determinados serviços".
} 
imperícia ou imprudência, uma vez que sua responsabilidade civil está fundamentada na culpa.

\begin{abstract}
RESPONSABILIDADE CIVIL. DANO MORAL E MATERIAL. CLÍNICA VETERINÁRIA. MORTE DE ANIMAL DE ESTIMAÇÃO APÓS A REALIZAÇÃO DE PROCEDIMENTO CLÍNICO. AUSÊNCIA DE PROVA DA CONDUTA CULPOSA DO RÉU. DEVER DE INDENIZAR NÃO CONFIGURADO. SENTENÇA DE IMPROCEDÊNCIA MANTIDA POR SEUS PRÓPRIOS FUNDAMENTOS. 1. Incontroverso o óbito do cachorro de estimação da parte autora, após procedimento clínico realizado pelo réu, médico veterinário. A discussão cinge-se acerca da culpa do demandado, a quem a parte autora atribui conduta negligente e imperita, sustentando a ocorrência de erro no procedimento. 2. A responsabilidade do médico veterinário, profissional liberal prestador de serviços, é subjetiva, nos moldes do artigo $14, \S 4^{\circ}$ do Código de Defesa do Consumidor. Dessa forma, a imputacão de responsabilidade prescinde da efetiva comprovação da ocorrência de culpa, ônus que se atribui ao autor. 3. No caso concreto, inexiste nos autos prova da ocorrência de negligência ou imperícia. A parte autora não produz qualquer prova nesse sentido, comprovando apenas o atendimento do animal pelo réu, o que, repisa-se, sequer é controvertido. A questão poderia, talvez, ser esclarecida pela realização de exame necroscópico, medida não adotada pela parte autora. Ademais, ainda que restasse demonstrada a ocorrência do óbito em razão da presença na região craniana do contraste utilizado no procedimento, seria necessária, ainda, a demonstração da má administração do produto pelo réu, com a comprovação do nexo causal. 4. As explicações trazidas em contestação, por outro lado, se mostram absolutamente plausíveis e demonstram que, como é comum em qualquer procedimento, o risco de complicações naturais no exame realizado existe, conferindo verossimilhança à defesa. 5. Assim, diante da ausência de qualquer elemento probatório acerca de eventual conduta culposa no agir do médico veterinário demandado, conclui-se que a autora não se desincumbiu do ônus de comprovar os fatos constitutivos de seu direito, nos termos do art. 333, inciso I, do código de processo civil, impondo-se a manutenção da sentença de improcedência. 6. Sentença de improcedência confirmada pelos próprios fundamentos, nos termos do art. 46 da Lei n. 9.099/95. Recurso desprovido. (TJRS; RecCv 26855-06.2012.8.21.9000; Porto Alegre; Segunda Turma Recursal Cível; Rel. Des. Carlos Eduardo Richinitti; Julg. 21/05/2013; DJERS 27/05/2013).
\end{abstract}

Oscar Ivan Prux (PRUX, 1998, p. 107)conceitua profissional liberal como "Uma categoria de pessoas, que no exercício de suas atividades laborais, é perfeitamente diferenciada pelos conhecimentos técnicos reconhecidos em diploma de nível superior, não se confundido com a figura do autônomo." O médico veterinário é um profissional liberal.

A responsabilidade civil do profissional liberal é uma exceção quanto à responsabilidade adotada pelo Código de Defesa do Consumidor, uma vez que o parágrafo 4. ${ }^{\circ}$, do art. 14 estabelece que "A responsabilidade pessoal dos profissionais liberais será apurada mediante a verificação de culpa." Cabendo ao profissional liberal (médico veterinário) a prova que não agiu com negligência, imprudência ou imperícia. Cabe ao profissional liberal (médico veterinário) o ônus de provar que não agiu com culpa (negligência, imprudência ou imperícia), quando seu cliente sofrer algum dano em razão da 
prestação de serviços, torna-se de extrema importância o arquivo de todo o prontuário, inclusive o termo de consentimento informado que deve ser assinado pelo cliente.

Sobre a responsabilidade civil do profissional liberal no Código de Defesa do Consumidor, imprescindível os ensinamentos de Antônio Herman Vasconcelos Benjamin:

O Código, em todo o seu sistema, prevê uma única exceção ao princípio da responsabilização objetiva para os acidentes de consumo: os serviços prestados por profissionais liberais. Não se introduz sua irresponsabilidade, limitando-se o dispositivo legal a afirmar que a apuração de responsabilidade far-se-á com base no sistema tradicional baseado em culpa. Só nisso são eles beneficiados. No mais, submetem-se, integralmente, ao traçado do Código.[...]

A exceção aplica-se, por conseguinte, apenas ao próprio profissional liberal, não se estendendo às pessoas jurídicas que integre ou para as quais prestem serviço. O Código é claro ao asseverar que só para a "responsabilidade pessoal" dos profissionais liberais é que se utiliza o sistema alicerçado em culpa. Logo, se o médico trabalhar para um hospital, responderá ele apenas por culpa, enquanto a responsabilidade civil do hospital será apurada objetivamente.

[...] Qualquer defeito em um deles sujeitará o seu fornecedor (desde que não seja profissional liberal) à responsabilização objetiva (BENJAMIN; MARQUES; BESSA, 2007, p. 137).

Isso significa que a responsabilidade civil do médio veterinário, enquanto, profissional liberal será apurada mediante negligência, imprudência ou imperícia, diferentemente, da clinica veterinária e do pet shop que responderão por danos causados aos animais independente de culpa.

A jurisprudência é pacífica nesse sentido, o Tribunal de Justiça de Minas Gerais já decidiu que a responsabilidade do médico veterinário (profissional liberal) é subjetiva, fundamentada no elemento culpa:

AÇÃO DE INDENIZAÇÃO. ÓBITO DE ANIMAL DE ESTIMAÇÃO. RESPONSABILIDADE SUBJETIVA DO VETERINÁRIO. PROVA DE QUE O PROFISSIONAL IMPEDIU O ACESSO DO PROPRIETÁRIO AO ANIMAL, ALÉM DE TER REALIZADO O SEU DESCARTE EM ATERRO SANITÁRIO. DANOS MORAIS. Estando demonstrado nos autos que não obstante o comparecimento da dona do animal de estimação na clínica veterinária do recorrido este não permitiu que ela visse e resgatasse seu animal já falecido, e após este fato, ainda determinou o descarte do corpo em aterro sanitário, deve ser reconhecida a ilicitude da conduta, bem como a caracterização do dano moral advindo do fato. $\mathrm{O}$ valor da indenização por danos morais deve ser apto a compensar o sofrimento derivado da violação de direito da personalidade. (TJMG; APCV 1.0525.11.016003-9/001; Rel. Des. Pedro Bernardes; Julg. 24/11/2015; DJEMG 18/12/2015).

A exceção é exclusiva ao profissional liberal (responsabilidade subjetiva), assim sendo, como regra geral, não se aplica essa teoria à clínica veterinária e ao pet shop, as quais responderão com base na responsabilidade objetiva. Nesse sentido, já decidiu o Tribunal de Justiça de São Paulo em relação ao pet shop: 
RESPONSABILIDADE CIVIL. FATO DO SERVIÇO. Morte de animal de estimação após tosa em "PET shop". Animal golpeado na cabeça com aparelho utilizado no procedimento de tosa. Irrelevância da absolvição da ré no âmbito criminal, se não decorrente de constatação da não ocorrência do fato ou da não autoria pela ré. Art. 935 do CC. Ato do preposto. Art. 34 do CDC. Responsabilidade objetiva do fornecedor de serviços. Art. 14, caput e $\S 1^{\circ}$, II do CDC. Não comprovada qualquer excludente de responsabilidade. Dano moral in Res ipsa. Precedente. Mantida a indenização em R\$ 30.000,00 porque bem atendidos os critérios de proporcionalidade e razoabilidade. Observado, em especial, o caráter punitivo da indenização, seja pela crueldade e violência perpetrada contra animal pelo qual tinham as rés o dever de cuidado, seja pela atitude reprovável da fornecedora após o ocorrido e no decorrer do processo. Mantida, ainda, a condenação nas penas de litigância de má-fé por alterar, a corré, a verdade dos fatos. Igualmente, não comporta qualquer retoque a decisão quanto à fixação dos honorários sucumbenciais nem quanto à distribuição do ônus da sucumbência. Respeitados os parâmetros legais. Inteligência da Súmula $\mathrm{n}^{\circ} 326$ do Egrégio STJ. Recursos desprovidos. (TJSP; APL 0046802-34.2009.8.26.0554/50000; Ac. 6174039; Santo André; Sexta Câmara de Direito Privado; Rel ${ }^{a}$ Des $^{a}$ Ana Lúcia Romanhole Martucci; Julg. 13/03/2014; DJESP 12/06/2014))

Dessa forma, a responsabilidade civil do médico veterinário é apurada mediante a culpa, por ser intuito personae, caracteriza-se por subjetiva, ou seja, só responderá por negligência, imprudência ou imperícia, e, da clínica veterinária e do pet shop a responsabilidade, regra geral, é objetiva, ou seja, responde independentemente de culpa.

Como qualquer outro profissional, o médico veterinário deve cumprir também as normas estabelecidas pelo seu Conselho Federal, no caso ao Conselho Federal de Medicina Veterinária.

\section{CONCLUSÃO}

O direito é indispensável para a vida em sociedade, pois pressupõe algumas restrições à conduta humana, com o fito de manter a ordem. É impossível imaginar uma sociedade sem normas de conduta.

A responsabilidade civil é o dever que o indivíduo tem de indenizar os danos causados a outro; e esse dever vem desde que a sociedade existe, visto que o homem sempre repugnou a lesão a seu semelhante.

A responsabilidade civil não se origina apenas dos atos ilícitos; esta pode ter origem em atos lícitos, como é o caso dos serviços prestados pelo pet shop, médico e clínica veterinária, que, muitas vezes, comercializam produtos, que também configura uma atividade lícita, mas, isso não os exime de indenizar os danos causados a seus clientes.

O Código Civil preferiu como regra, a responsabilidade subjetiva; no entanto, adotou, também, a responsabilidade objetiva.

O termo dano envolve uma diminuição no patrimônio de uma pessoa, em razão da ação de outrem. No caso dos clientes dono de animais, os danos podem ser de caráter moral (estético) ou material.

O médico veterinário é um profissional liberal. A responsabilidade civil do profissional liberal é uma exceção quanto à responsabilidade civil (teoria objetiva) adotada pelo Código de Defesa do Consumidor, uma vez que o parágrafo $4 .^{\circ}$, do art. 14 estabelece que: "A responsabilidade pessoal dos profissionais liberais será apurada mediante a 
verificação de culpa." A responsabilidade do pet shop e da clínica veterinária, é classificada como objetiva, ou seja, desconsidera-se o elemento culpa.

Por tratar-se de relação de consumo, o cliente pode ter a seu favor a inversão do ônus da prova, ou seja, cabendo ao pet shop, médico e clínica veterinária provar que os danos alegados, não tiveram como origem a prestação de serviços.

\section{REFERÊNCIAS}

BARROS, Cristiane Gouveia. Grandes temas da atualidade dano moral. aspectos constitucionais, civis, penais e trabalhistas. Eduardo de Oliveira Leite (Coord.). Rio de Janeiro: Forense, 2002.

BENJAMIN, Antônio Herman Vasconcelos. MARQUES, Cláudia Lima. BESSA, Leonardo Roscoe. Manual de direito do consumidor. São Paulo: Editora Revista dos Tribunais, 2007.

BRASIL, Ávio. O dano moral no direito brasileiro. Rio de Janeiro: Livraria Jacinto Editora, 1944.

BRASIL. Código Civil. Disponível em: <http://www.planalto.gov.br/ccivil_03/LEIS/2002/L10406.htm>. Acesso em 23 fev. 2017.

BRASIL. Constituição Federal. $\quad$ Disponível em: http://www.planalto.gov.br/ccivil_03/constituicao/constituicaocompilado.htm>. Acesso em 23 fev. 2017.

CAVALIERI FILHO, Sergio. Programa de responsabilidade civil. 8 ed., São Paulo: Atlas, 2008.

DINIZ, Maria Helena. Curso de Direito Civil brasileiro: Responsabilidade civil, volume 7. 25. ed. São Paulo: Saraiva, 2011.

LOPES, Miguel Maria de Serpa. Curso de Direito Civil: Volume V Rio de Janeiro: Freitas Bastos, 1961.

PRUX, Oscar Ivan. A responsabilidade civil do profissional liberal no código de defesa do consumidor. Belo Horizonte: Del Rey, 1998.

RODRIGUES, Silvio. Direito Civil: responsabilidade civil, volume IV. 19. ed. atual. São Paulo: Forense, 2002.

SILVA, Luiz Cláudio, Responsabilidade Civil: teoria e prática das ações. Rio de Janeiro: Forense, 1998.

SILVA, Wilson Mello da. O dano moral e sua reparação. 2. ed. rev. e ampl. Rio de Janeiro: Forense, 1969.

TARTUCE, Flávio. Direito das obrigações e responsabilidade civil. Vol. 2. 11. ed. Rio de Janeiro: Forense, São Paulo: Método, 2016. 
TOMASZEWSKI, Adauto de Almeida. Separação, violência e danos morais: a tutela da personalidade dos filhos. São Paulo: Paulistana Jur, 2004. 